\title{
Red-to-NIR Emissive Radical Cations Derived from Simple Pyrroles
}

\section{for Bio-Imaging}

\author{
Lihua Zheng, ${ }^{\dagger}$ Wenchao Zhu, ${ }^{\dagger}$ Zikai Zhou, ${ }^{\dagger}$ Kai Liu, ${ }^{*}$ Meng Gao, ${ }^{*}$ and
}

\author{
Ben Zhong Tang*
}

Lihua Zheng, Wenchao Zhu, Zikai Zhou, Prof. Dr. Meng Gao

National Engineering Research Center for Tissue Restoration and Reconstruction, Key Laboratory of Biomedical Engineering of Guangdong Province, Key Laboratory of Biomedical Materials and Engineering of the Ministry of Education, Innovation Center for Tissue Restoration and Reconstruction, School of Biomedical Science and Engineering, School of Materials Science and Engineering, South China University of Technology, Guangzhou 510006, China E-mail: msmgao@scut.edu.cn

Prof. Dr. Kai Liu

Institute of Marine Drugs, Guangxi University of Chinese Medicine, Nanning 530200, China. E-mail: kailiu@outlook.com

Prof. Dr. Ben Zhong Tang

AIE institute, State Key Laboratory of Luminescent Materials and Devices, Center for Aggregation-Induced Emission, Guangdong Provincial Key Laboratory of Luminescence from Molecular Aggregates, Guangzhou International Campus, South China University of Technology (SCUT), Guangzhou 510640; Department of Chemistry, Hong Kong Branch of Chinese National Engineering Research Center for Tissue Restoration and Reconstruction and Institute for Advanced Study, The Hong Kong University of Science and Technology, Kowloon, Hong Kong 999077; Shenzhen Institute of Aggregate Science and Technology, School of Science and Engineering, The Chinese University of Hong Kong, Shenzhen 518172, China. E-mail: tangbenz@cuhk.edu.cn

[†] These authors contributed equally to this work.

\begin{abstract}
Red-to-near-infrared (NIR) fluorophores are highly desirable for bio-imaging with advantages of excellent tissue penetration ability and less interference from autofluorescence, but their synthesis usually require tedious procedures and it's thus highly desirable for red-to-NIR fluorophores directly generated from easily available substrates. Compared with the conventional closed-shell fluorophores, radical cations are featured with a large red-shift absorption, but most of them are not fluorescent due to the fast internal conversion between excited and ground state with a small energy gap. Moreover, radical cations suffer from instability because they can easily undergo radical coupling or nucleophilic addition reactions. Herein, we found that 2,5-
\end{abstract}


dimethylpyrroles can rapidly generate red-to-NIR emissive radical cations, which can be stabilized by adsorption on thin layer chromatography (TLC) plate or being encapsulated in cucurbit[7]uril (CB[7]). The NIR-emissive radical cations derived from pyrroles were verified by electron paramagnetic resonance (EPR) spectroscopy and theoretical calculations. Importantly, the pyrrole-derived radical cations encapsulated in $\mathrm{CB}$ [7] can be used for mitochondrial imaging in living cells and tumor imaging in vivo with a high signal-to-noise ratio. The easily available and NIR-emissive radical cations derived from simple pyrroles are promising for applications in biomedical study. 


\section{Introduction}

The red-to-near-infrared (NIR) fluorophores are highly desirable for bio-imaging with advantages of excellent tissue penetration ability and less interference from autofluorescence. ${ }^{[1]}$ However, their structures are usually composed with electrondonating/-withdrawing groups connected by lengthy conjugation units, which require tedious procedures for their preparation. ${ }^{[2]}$ Therefore, it's highly desirable for facile preparation of red-to-NIR emissive fluorophores from easily available substrates. ${ }^{[3]}$ Compared with the conventional closed-shell fluorophores, radical cations are featured with signficantly red-shift absorption, but very few of them are fluorescent due to the fast internal conversion between excited and ground state with a small energy gap. ${ }^{[4]}$ Moreover, the stability of radical cations are usually very poor in solution because they can easily undergo further reactions, such as radical coupling, bond cleavage or nucleophilic addition reactions. ${ }^{[5]}$

The 2,5-dihydropyrroles are featured with a strong electron donating ability and can be easily oxidized to afford oligo- or poly-pyrroles for optoelectronic applications via unstable radical cation intermediates. ${ }^{[6]}$ Herein, we unexpectedly found that the 2,5dimethylpyrroles can easily generate stable and red-to-NIR emissive radical cations by adsorption on thin layer chromatography (TLC) plate or being encapsulated in cucurbit[7]uril ( $\mathrm{CB}[7])$. Moreover, the pyrrole-derived radical cation encapsulated in $\mathrm{CB}[7]$ can be used for mitochondrial imaging in living cells and tumor imaging in vivo with an excellent signal-to-noise ratio and long-term stability (Scheme 1). 


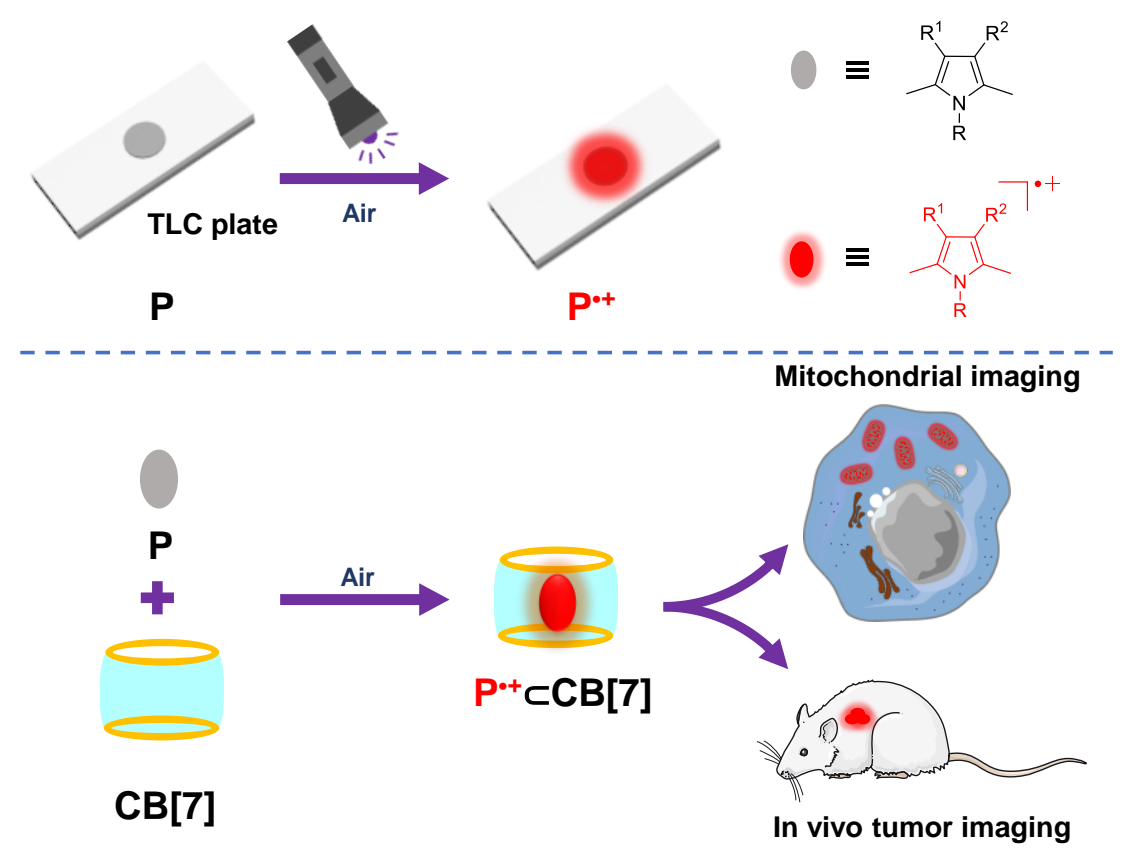

Sheme 1. The 2,5-dimethylpyrroles derived NIR-emissive radical cations stabilized by adsorption on TLC plate or being encapsulated in $\mathrm{CB}[7]$ and their applications for mitochondrial and tumor imaging.

\section{Results and Discussion}

The pyrrole compunds P1-P10 in Figure 1 are commercially available or can be easily prepared by Paal-Knorr reaction from 1,4-butanediones and primary amines (Figure S1-S6). ${ }^{[7]}$ We first investigated the photophysical properties of pyrrole compound P1 decorated with $\mathrm{N}$-phenyl and 2,5-dimethyl substituents, which in THF solution exibited a maximum absorption and emission at 245 and $305 \mathrm{~nm}$, respectively (Figure 1A). To our surprise, when it was dropped on silica gel-coated thin layer chromatography (TLC) plate under air, a red fluroescence emission was observed with a maximum excitation and emission wavelength at 600 and $630 \mathrm{~nm}$, respectively (Figure 1B). Compared with the control group under dark, an accelerated generation of red fluorescence was observed under UV irradiation $(365 \mathrm{~nm})$ and the fluorescence intensity at $630 \mathrm{~nm}$ quickly increased to a plateau within $30 \mathrm{~min}$ (Figure 1C-D, Figure S7). It's noteworthy that the maximum emission at $630 \mathrm{~nm}$ is independent of the excitation wavelength (Figure S8). Importantly, the generation of red fluorescence was efficiently inhibited 
under argon, which indicates oxygen in air is neccesary for generation of fluorophores with red fluoresence (Figure S9). ${ }^{[8]}$ We suppose that the electron-rich pyrrole P1 can undergo single electron oxidation promoted by oxygen to generate radical cation $\mathbf{P} 1^{{ }^{\bullet+}}$, which can be stabilized by the porous silica gel and emit red fluorescence. ${ }^{[9]}$ The in situ generated $\mathbf{P 1}^{\circ+}$ on TLC plate showed a quantum yield of $8.54 \%$ and a lifetime of 1.63 ns (Figure S10, Table S1), which suggests it's promising for bio-imaging applications.

We then investigated the substituent effect of pyrroles for the generation of radical cations (Figure 1E-L, Figure S11-S12). Compounds $\mathbf{P 2}$ and $\mathbf{P 3}$ with 2,5-dihydrogen or 2,5-diphenyl subsitutents on TLC plate showed a very weak fluorescence signal (Figure S11A-D), while compound P4 with 2-phenyl-5-methyl substituent showed a slowly increased red fluorescence under UV irradiation for $120 \mathrm{~min}$ (Figure S11E-F). Compound P5 decorated with an electron-withdrawing 3-aldehyde group on the pyrrole ring showed a very weak fluorescence signal even after a long-term UV irradiation (Figure S11G-H). In contrary, compound P6 with 3-hydroxylmethyl group on the pyrrole ring showed a high efficiency for generation of $\mathbf{P 6}{ }^{\mathbf{}^{+}}$within 5 min (Figure 1E$\left.\mathrm{F}, \lambda_{\mathrm{em}}=670 \mathrm{~nm}, \Phi_{\mathrm{F}}=11.32 \%, \tau=2.22 \mathrm{~ns}\right)$. These results suggest that the electron-rich pyrroles decorated with alkyl groups are beneficial for the generation of radical cations. We further investigated the effect of $N$-substituents for the generation of radical cations. Interestingly, compared with compound P7 decorated with electron-donating $\mathrm{N}$-(4-methoxyphenyl) substituent for generation of $\mathbf{P} 7^{\bullet+}$ with UV irradiation for 120 $\min \left(\right.$ Figure $\left.1 \mathrm{G}-\mathrm{H}, \Phi_{\mathrm{F}}=7.22 \%, \tau=1.87 \mathrm{~ns}\right)$, compound $\mathbf{P 8}$ decorated with $\mathrm{N}$-(4carboxylic acid phenyl) substituent showed a much higher efficiency for generation of radical cation $\mathbf{P 8}^{\circ+}$ within 3 min (Figure 1I-J, $\Phi_{\mathrm{F}}=9.59 \%, \tau=1.64 \mathrm{~ns}$ ). Moreover, compound P9 with $N$-methyl group showed a high efficiency for generation of $\mathbf{P 9}^{\bullet+}$ within 15 min (Figure $1 \mathrm{~K}-\mathrm{L}, \Phi_{\mathrm{F}}=4.86 \%, \tau=1.93 \mathrm{~ns}$ ), but compound P10 with $N-\mathrm{H}$ group showed a much lower efficiency for generation of the corresponding radical cation $\mathbf{P 1 0}^{\circ+}$ (Figure S11I-L). 

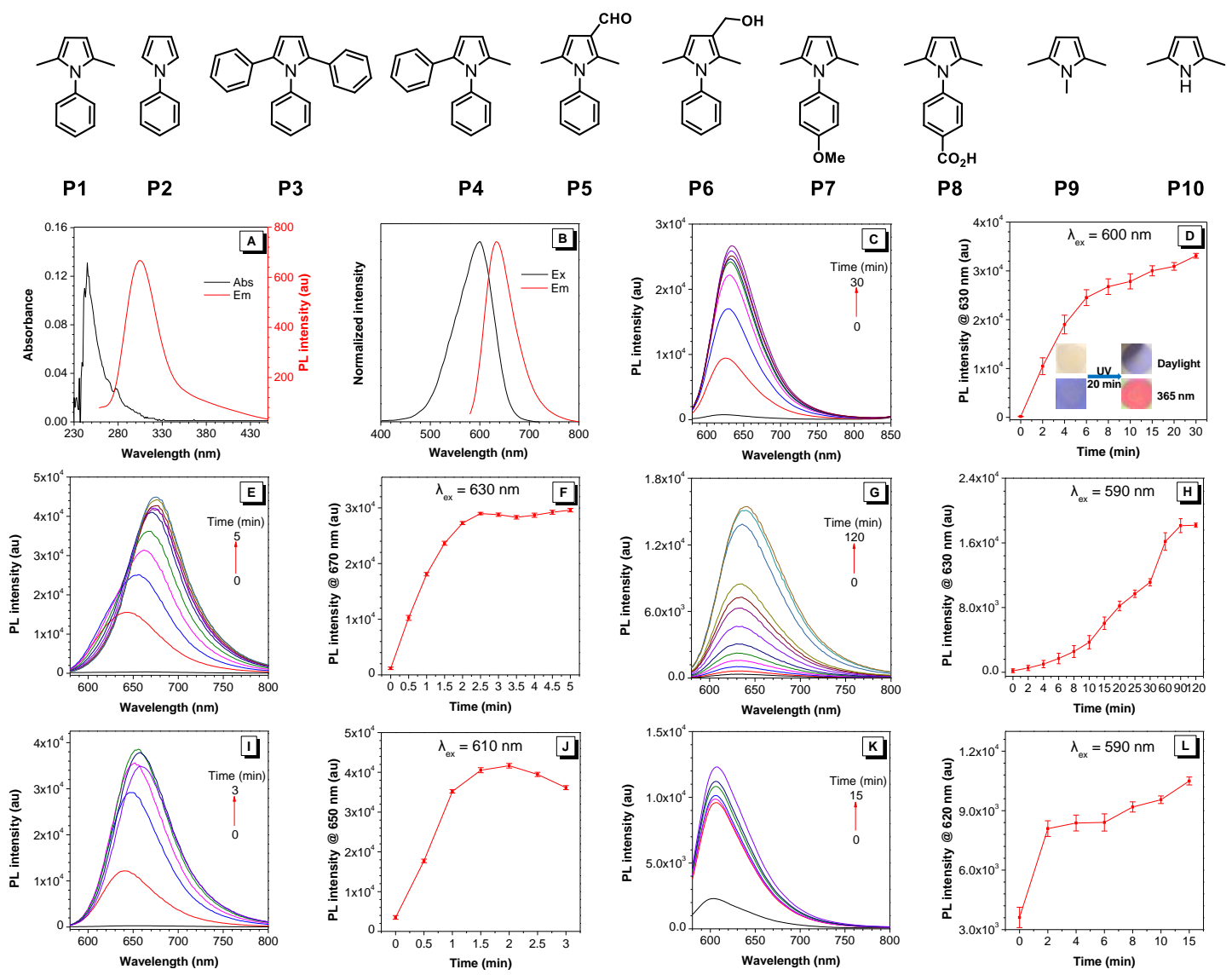

Figure 1. (A) UV-Vis absorption and fluorescence spectra of P1 in THF (10 $\mu \mathrm{M})$; (B)

Exciation and emission spectra of $\mathbf{P} 1^{\bullet+}$ on TLC plate; (C) PL spectra of in situ generated $\mathbf{P 1}^{{ }^{++}}$on TLC plate under air and $365 \mathrm{~nm}$ light irradiation for different time; (D) Plots of relative PL intensity of $\mathbf{P 1}^{{ }^{\bullet+}}$ at $630 \mathrm{~nm}$ versus irradiation time; Insets are photos of $\mathbf{P 1}$ and in situ generated $\mathbf{P 1}^{{ }^{++}}$on TLC plate under daylight and UV light; (E, G, I, K) PL spectra of in situ generated $\mathbf{P 6}^{\cdot+}, \mathbf{P 7}^{{ }^{++}}, \mathbf{P 8}^{\bullet+}, \mathbf{P 9}^{\cdot+}$ on TLC plate under $365 \mathrm{~nm}$ light irradiation for different time; $\lambda_{\mathrm{ex}}=550 \mathrm{~nm} ;(\mathrm{F}, \mathrm{H}, \mathrm{J}, \mathrm{L})$ Plots of relative PL intensity of $\mathbf{P 6}^{{ }^{+}}, \mathbf{P 7}^{{ }^{++}}, \mathbf{P 8}^{\bullet+}, \mathbf{P 9}^{\bullet+}$ at $670,630,650$ and $620 \mathrm{~nm}$ versus irradiation time, respectively.

To verify the generation of radical cations, we then measured their electron paramagnetic resonance (EPR) spectra. Because compound $\mathbf{P 6}{ }^{\bullet+}$ showed the highest emission efficiency, it was chosen as the model compound. As shown in Figure 2A, a single line signal was observed for the in situ generated $\mathbf{P 6}{ }^{\mathbf{O}^{+}}$adsorbed on silica gel powder with $g=2.003$, which suggests the existence of unpaired electron and is in good 
agreement with the calculated EPR spectrum. ${ }^{[10]}$ For other pyrrole compounds, they also showed a similar single line signal with $g \sim 2.003$ (Figure S13). The redox properties of $\mathbf{P 6}$ were then examined by cyclic voltammetry in $\mathrm{CH}_{2} \mathrm{Cl}_{2}$ at room temperature, which exhibited an irreversible oxidation wave with a low oxidation potential $\left(E_{\mathrm{ox}}=+0.62 \mathrm{~V}\right.$ vs Fc/Fc ${ }^{+}$, Figure $\left.2 \mathrm{~B}\right)$. Moreover, pyrroles P1 and P7-P9 with high efficiencies for generation of red-to-NIR fluorescence signals also showed irreversible low oxidation potentials (Figure S14, Table S2, $E_{\mathrm{ox}}=+0.53-0.73 \mathrm{~V}$ vs $\mathrm{Fc} / \mathrm{Fc}^{+}$). These results suggest that electron-rich pyrroles can easily undergo oxidation reaction to generate radical cations.

We then prepared $\mathbf{P 6}^{-+}$in $\mathrm{CH}_{2} \mathrm{Cl}_{2}$ solution with silver hexafluoroantimonate $\left(\mathrm{AgSbF}_{6}\right)$ as the one-electron oxidant. ${ }^{[11]}$ A maximum absorption and emission intensity at 633 and $676 \mathrm{~nm}$ was respectively observed for the in situ generated $\mathbf{P 6}{ }^{\circ+}$ within 60 min (Figure 2C-F). Further reaction led to a new absorption peak at $460 \mathrm{~nm}$ and disappearance of the absorption and emission peaks at 633 and $676 \mathrm{~nm}$, respectively. These results indicates that $\mathbf{P 6}^{-+}$in $\mathrm{CH}_{2} \mathrm{Cl}_{2}$ solution may undergo further coupling reactions. In contrary, the in situ generated $\mathbf{P 6}^{\mathbf{}}$ on TLC plate showed a much higher stability for at least $240 \mathrm{~min}$ (Figure S15). These results verified that the pyrrole-derived radical cations can be stabilized by adsorption on porous silica gel. 

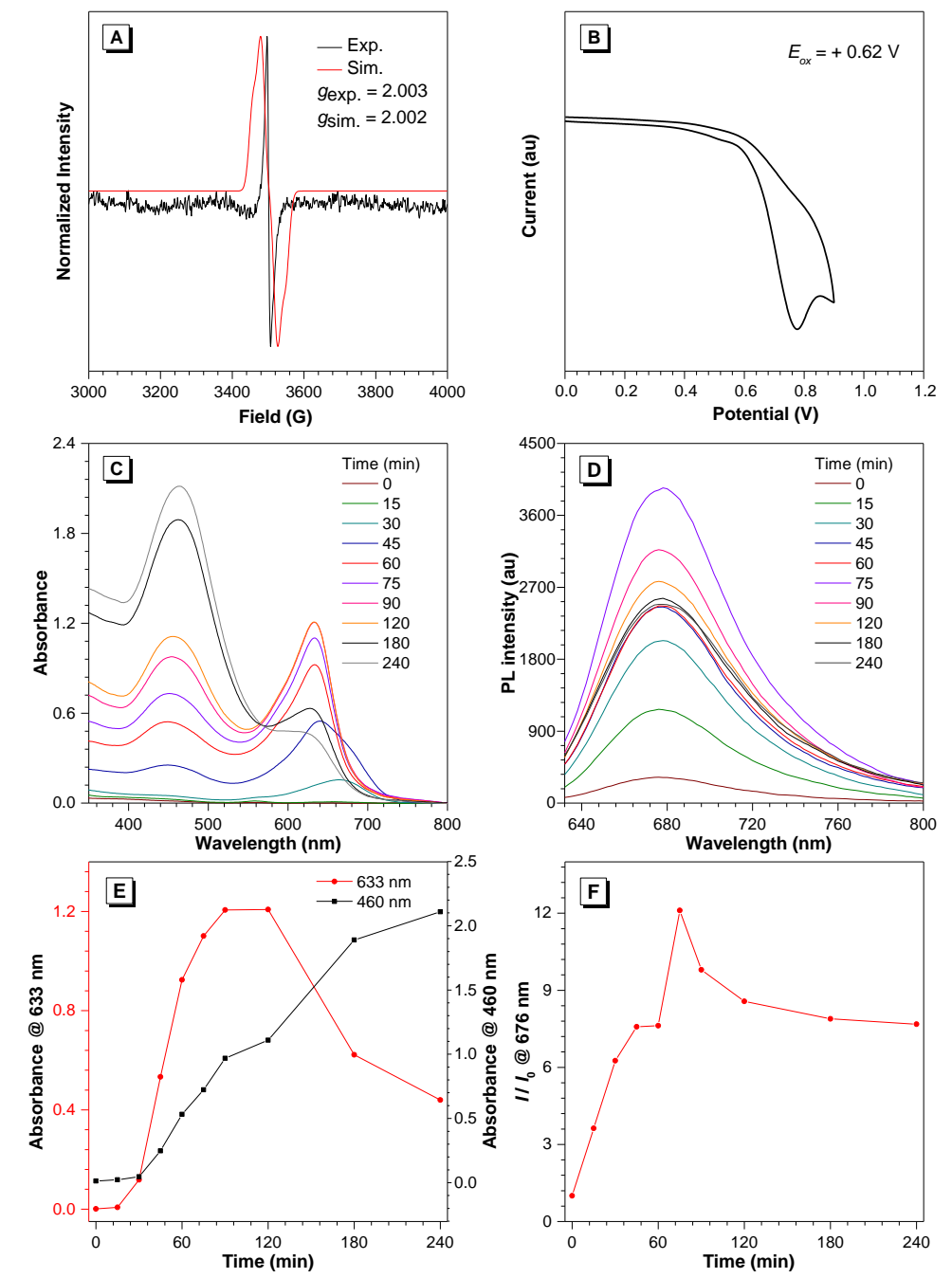

Figure 2. (A) Experimental and calculated EPR spectra of $\mathbf{P 6}{ }^{{ }^{+}}$absorbed on silica gel;

(B) Cyclic voltammogram (oxidation) of $\mathbf{P 6}^{\cdot+}$ in $\mathrm{CH}_{2} \mathrm{Cl}_{2}$ containing $0.1 \mathrm{M} n-\mathrm{Bu}_{4} \mathrm{NPF}_{6}$;

(C, D) Time-dependent UV-Vis absorption and PL spectra of $\mathbf{P 6}^{\mathbf{+}}$ in $\mathrm{CH}_{2} \mathrm{Cl}_{2}$ with $\mathrm{AgSbF}_{6}$ as the oxidant; (E, F) Plots of absorbance intensity of $\mathbf{P 6}^{{ }^{++}}$in $\mathrm{CH}_{2} \mathrm{Cl}_{2}$ at 633 $\mathrm{nm}$ and $460 \mathrm{~nm}$ and PL intensity $I / I_{0}$ at $676 \mathrm{~nm}\left(\lambda_{\mathrm{ex}}=600 \mathrm{~nm}\right)$ versus reaction time.

To further get insight into the photophysical properties of pyrrole radical cations, energy levels of the frontier molecular orbitals of $\mathbf{P 6}^{{ }^{\circ+}}$ were calculated based on density

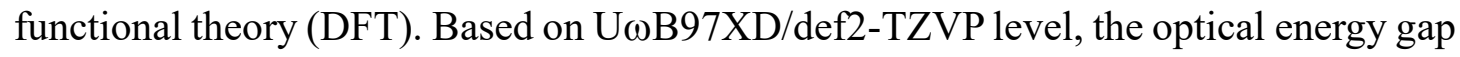
for $\mathbf{P 6}^{{ }^{+}}$was calculated to be $1.96 \mathrm{eV}(631 \mathrm{~nm})$, which agrees well with experimental value $(633 \mathrm{~nm})$ and can be ascribed to the $\mathrm{D}_{0} \rightarrow \mathrm{D}_{1}$ transition consisting of $\beta-\mathrm{NH}-3$ to 
$\beta$-SUMO (37.6\%), $\beta$-NH-2 to $\beta$-SUMO (30.6\%) and $\beta$-SOMO to $\beta$-SUMO (29.2\%)

(Figure 3A). The Mulliken spin population distribution of $\mathbf{P 6}{ }^{-+}$radical indicates that the single electron mainly locates at the pyrrole ring, especially the C-2 and C-5 position (Figure 3B). Therefore, the exceptional stability of the 2,5-dimethyl substituted pyrroles can be ascribed to the steric shielding of the reactive positions of $\mathrm{C}-2$ and $\mathrm{C}-5$ by the methyl substituents, and the electron-donating alkyl substituent can further stabilize the radical cations through $\delta-\pi$ hyperconjugation effect. ${ }^{[12]}$

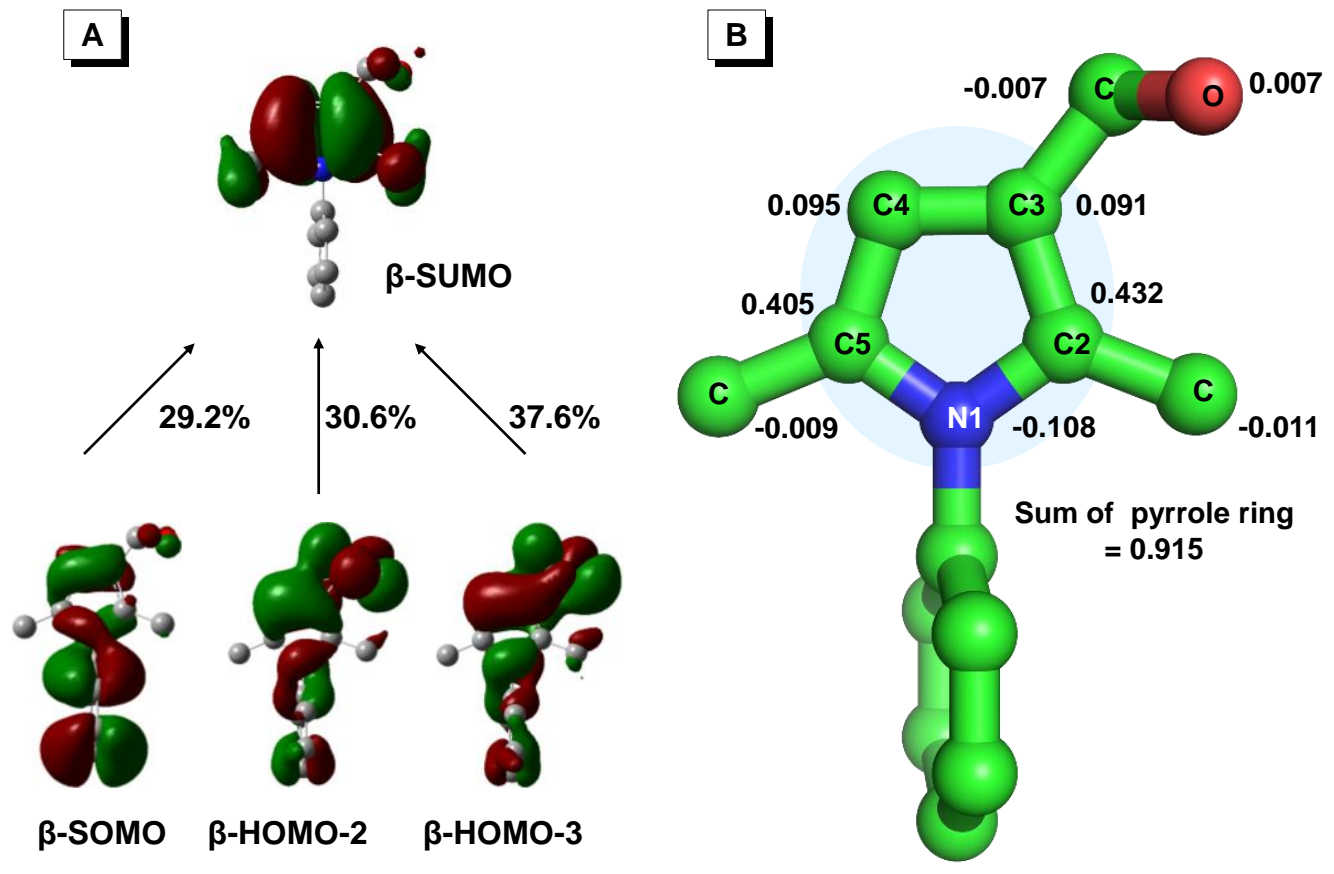

Figure 3. (A) Molecular orbitals and (B) Mulliken spin distribution of $\mathbf{P 6} \mathbf{6}^{-+}$. The spin density was drawn at the isovalue of $4 \times 10^{-4} \mathrm{e} / \mathrm{bohr}^{3}$. Positive and negative values respectively refer to $\alpha$ and $\beta$ electron spin. Hydrogen atoms are omitted for clarity.

We then used the supramolecular host cucurbit[7]uril (CB[7]) to stabilize the pyrrole-derived radical cation. ${ }^{[13]}$ After screening experiment (Figure S16), we found that the mixture of $\mathbf{P 6}$ and CB[7] under air quickly became clear under sonication and showed a light blue color, which suggests that $\mathbf{P 6}$ can quickly transform into $\mathbf{P 6}{ }^{\mathbf{+}}$ and further being encapsulated by $\mathrm{CB}[7]$ to generate $\mathbf{P 6}^{{ }^{*+}} \subset \mathrm{CB}[7]$ complex with NIR emission (Figure 4A-B). Moreover, the formation of $\mathbf{P 6}^{\bullet+}$ in the presence of $\mathrm{CB}[7]$ was 
verified by EPR spectra (Figure S13). The $\mathbf{P 6}^{{ }^{++}} \subset \mathrm{CB}[7]$ complex in aqueous solution showed a stable absorption and emission spectra at room temperature under air for at least 240 min without any apparent decrease (Figure S17). Its markedly enhanced stability can be attributed to the interaction between the pyrrole cation radical and the hydrophobic cavity with a slightly negative electrostatic potential (Figure S18). ${ }^{[14]}$

We then investigated the application of the pyrrole radical cations for cell imaging. The CLSM images of HeLa and A375 cells stained by $\mathbf{P 6}^{{ }^{+}} \subset \mathrm{CB}[7]$ complex showed a red fluorescence signal, which mainly distributed in mitochondria and was verified by co-staining with MitoTracker Green (Figure 4C). The Lambda mode scanning further verified the red fluorescence emission generated from radical cation of $\mathbf{P 6}^{\mathbf{}}{ }^{+}$with a maximum emission wavelength at $\sim 670 \mathrm{~nm}$ (Figure S19). Importantly, the $\mathbf{P} \mathbf{6}^{{ }^{+} \subset \mathrm{CB}[7]}$ complex can be used for in vivo tumor imaging with an excellent fluorescence signal stability and tumor retention ability for at least $24 \mathrm{~h}$ (Figure 4D). These results suggest that $\mathbf{P 6}^{\cdot+} \subset \mathrm{CB}[7]$ complex is suitable for bio-imaging study with a low cytotoxicity (Figure S20). 

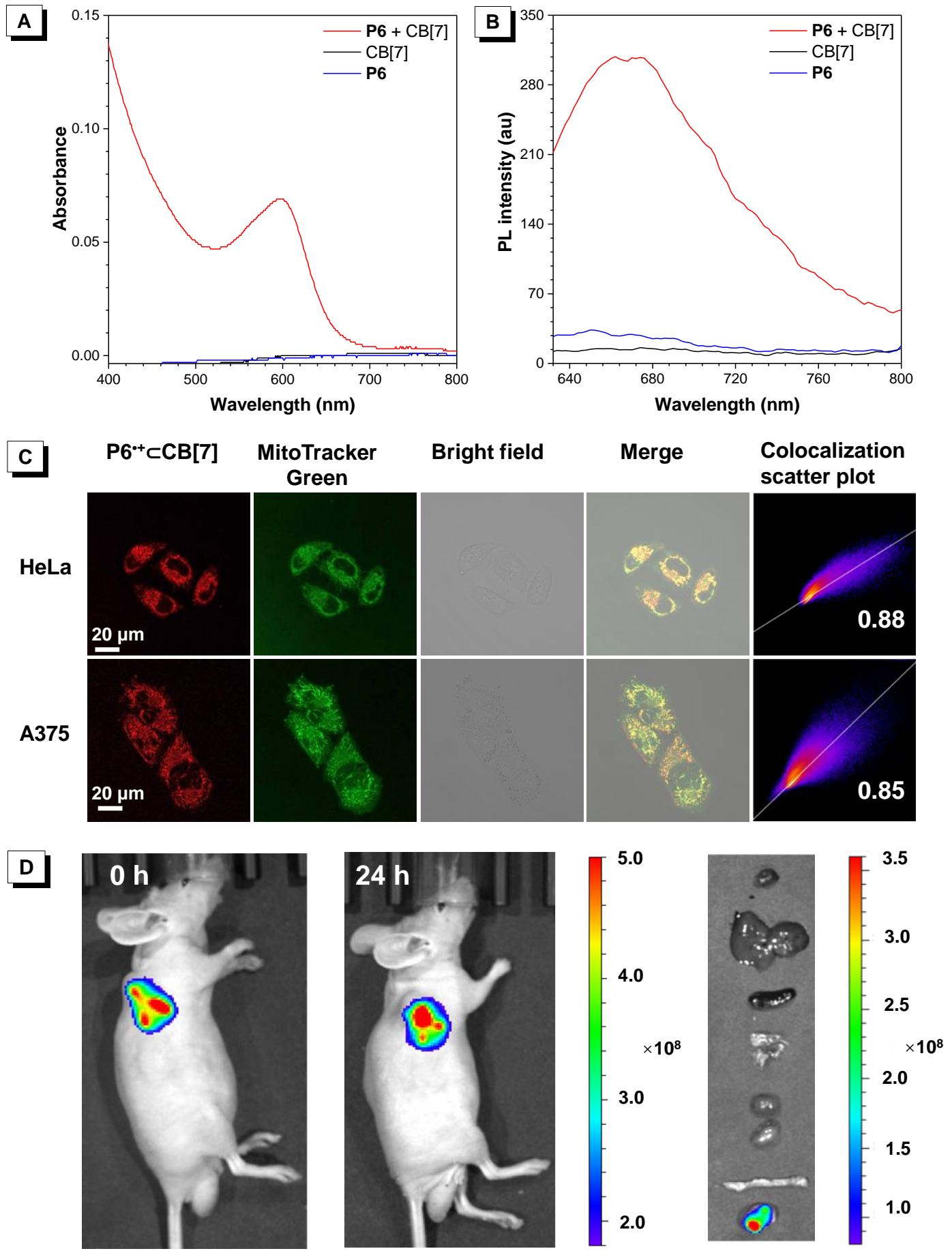

Figure 4. (A, B) UV-Vis absorption and PL spectra of P6, CB[7] and "P6 + CB[7]"; $[\mathrm{P} 6]=300 \mu \mathrm{M}, \mathrm{CB}[7]=100 \mu \mathrm{M}$; (C) Colocalization images of $\mathbf{P 6}^{{ }^{+}} \subset \mathrm{CB}[7]$ and MitoTracker Green in living HeLa and A375 cells; For $\mathbf{P 6}{ }^{*+} \subset \mathrm{CB}[7], \lambda_{\mathrm{ex}}=633 \mathrm{~nm}$; $\lambda_{\mathrm{em}}$ $=640-750 \mathrm{~nm}$; for MitoTracker Green, $\lambda_{\mathrm{ex}}=488 \mathrm{~nm} ; \lambda_{\mathrm{em}}=500-550 \mathrm{~nm}$; (D) Left: In vivo tumor images at 0 and $24 \mathrm{~h}$ after injection of $\mathbf{P 6}{ }^{{ }^{+}} \subset \mathrm{CB}[7]$; Right: fluorescence 
images of anatomic organs after $24 \mathrm{~h}$ (from top to bottom: heart, liver, spleen, lung, kidney, small intestine and tumor), $\lambda_{\mathrm{ex}}=608 \mathrm{~nm}, \lambda_{\mathrm{ex}}=680 \mathrm{~nm}$.

\section{Conclusions}

In conclusion, we unexpectedly found that stable and red-to-NIR emissive radical cations can be easily obtained from 2,5-dimethylpyrroles. Their excellent stability can be ascribed to the restriction of radical coupling reactions by blocking of the reactive positions of C-2 and C-5 with methyl groups and further adsorption on porous silica gel or being encapsulated in $\mathrm{CB}[7]$. The pyrrole-derived radical cations were verified by EPR spectra and theoretical calculations. Moreover, the $\mathbf{P 6}^{{ }^{++}} \subset \mathrm{CB}[7]$ complex can be used for mitochondrial imaging in living cells with a high signal-to-noise ratio and longterm in vivo tumor imaging. The further exploration of pyrrole-derived radical cations in biomedical study is under way in our laboratory.

\section{Acknowledgements}

This work was financially supported by the National Science Foundation of China (21788102, 51620105009, 21877040, U1801252); the National Key R\&D Program of China (2018YFC0311103); the Science and Technology Planning Project of Guangzhou (201804020060, 202007020002 and 201607020015); Natural Science Foundation of Guangdong Province (2020B1515020010); the Fundamental Research Funds for the Central Universities (2018JQ01); the Innovation and Technology Commission of Hong Kong (ITC-CNERC14SC01). K. L. is grateful for the financial support from Guangxi Scientific Research Funds (2020AC19056, 2020GXNSFAA297106) and the Special Fund for Hundred Talents Program and Bagui Scholars of Guangxi. The authors thank the kind help of Mr. Yakun Le for EPR 
measurements.

\section{Conflict of interest}

The authors declare no conflict of interest.

\section{References}

[1] a) L. Yuan, W. Lin, K. Zheng, L. He, W. Huang, Chem. Soc. Rev. 2013, 42, 622661; b) X. Cui, G. Lu, S. Dong, S. Li, Y. Xiao, J. Zhang, Y. Liu, X. Meng, F. Li, C.-S. Lee, Mater. Horiz. 2021, 8, 571-576.

[2] a) N. Karton-Lifshin, L. Albertazzi, M. Bendikov, P. S. Baran, D. Shabat, J. Am. Chem. Soc. 2012, 134, 20412-20420; b) S. Liu, H. Ou, Y. Li, H. Zhang, J. Liu, X. Lu, R. T. K. Kwok, J. W. Y. Lam, D. Ding, B. Z. Tang, J. Am. Chem. Soc. 2020, 142, 15146-15156; c) R. Liu, Y. Xu, K. Xu, Z. Dai, Aggregate 2021, DOI: 10.1002/agt2.23; d) C. Ji, L. Lai, P. Li, Z. Wu, W. Cheng, M. Yin, Aggregate 2021, DOI: $10.1002 /$ agt2.39.

[3] a) Y. Mu, Y. Liu, H. Tian, D. Ou, L. Gong, J. Zhao, Y. Huo, Y. Zhang, Z. Yang, Z. Chi, Angew. Chem. Int. Ed. 2021, 60, 6367-6371, Angew. Chem. 2021, 133, 64376441; b) X. Ai, Y. Chen, Y. Feng, F. Li, Angew. Chem. Int. Ed. 2018, 57, 2869-2873, Angew. Chem. 2018, 130, 2919-2923; c) H. Guo, Q. Peng, X. K. Chen, Q. Gu, S. Dong, E. W. Evans, A. J. Gillett, X. Ai, M. Zhang, D. Credgington, V. Coropceanu, R. H. Friend, J. L. Bredas, F. Li, Nat. Mater. 2019, 18, 977-984; d) Q. Peng, A. Obolda, M. Zhang, F. Li, Angew. Chem. Int. Ed. 2015, 54, 7091-7095, Angew. 
Chem. 2015, 127, 7197-7201.

[4] a) D. T. Breslin, M. A. Fox, J. Phys. Chem. 1994, 98, 408-411; b) K. Zimmer, B. Gödicke, M. Hoppmeier, H. Meyer, A. Schweig, Chem. Phys. 1999, 248, 263-271; c) Y. Yu, E. Gunic, B. Zinger, L. L. Miller, J. Am. Chem. Soc. 1996, 118, 10131018; d) S. Honda, R. Sugawara, S. Ishida, T. Iwamoto, J. Am. Chem. Soc. 2021, 143, 2649-2653; e) H. Murata, P. M. Lahti, J. Org. Chem. 2007, 72, 4974-4977; f) T. Nishinaga, Y. Sotome, J. Org. Chem. 2017, 82, 7245-7253; g) B. Z. Tang, J. W. Y. Lam, K. S. Wong, i. d. williams, H. H. Y. Sung, Z. He, Z. Zeng, J. Guo, Y. wang, P. Alam, C. Ma, J. Gong, Z. zhao, X. Zhao, 2020, DOI:10.26434/chemrxiv.12479321.v1; h) J. Grilj, E. N. Laricheva, M. Olivucci, E. Vauthey, Angew. Chem. Int. Ed. 2011, 50, 4496-4498, Angew. Chem. 2011, 123, $4589-4591$.

[5] a) A. Matsuura, T. Nishinaga, K. Komatsu, J. Am. Chem. Soc. 2000, 122, 1000710016; b) H. Yi, G. Zhang, H. Wang, Z. Huang, J. Wang, A. K. Singh, A. Lei, Chem. Rev. 2017, 117, 9016-9085; c) X. Chen, X. Wang, Z. Zhou, Y. Li, Y. Sui, J. Ma, X. Wang, P. P. Power, Angew. Chem. Int. Ed. 2013, 52, 589-592, Angew. Chem. 2013, 125, 617-620; d) M. Grzybowski, K. Skonieczny, H. Butenschoen, D. T. Gryko, Angew. Chem. Int. Ed. 2013, 52, 9900-9930, Angew. Chem. 2013, 125, 1008410115 ; e) M. Schmittel, A. Burghart, Angew. Chem. Int. Ed. 1997, 36, 2550-2589, Angew. Chem. 1997, 109, 2658-2699.

[6] a) S. H. Zhang, G. W. Lv, G. L. Wang, K. M. Zhu, D. M. Yu, J. Y. Shao, Y. Z. Wang, Y. H. Liu, J. Photochem. Photobiol. A 2015, 309, 30-36; b) M. N. Alberti, G. C. 
Vougioukalakis, M. Orfanopoulos, J. Org. Chem. 2009, 74, 7274-7282; c) J. K. Howard, K. J. Rihak, A. C. Bissember, J. A. Smith, Chem. Asian J. 2016, 11, 155167; d) A. Merz, J. Kronberger, L. Dunsch, A. Neudeck, A. Petr, L. Parkanyi, Angew. Chem. Int. Ed. 1999, 38, 1442-1446; Angew. Chem. 2012, 111, 1533-1538; e) V., Cooney, John, N., Hazlett, Robert, Heterocycles 1984, 22, 1513-1513; f) V. Amarnath, W. M. Valentine, K. Amarnath, M. A. Eng, D. G. Graham, Chem. Res. Toxicol. 1994, 7, 56-61; g) H. Yokoi, S. Hiroto, H. Shinokubo, J. Am. Chem. Soc. 2018, 140, 4649-4655; h) T. Nishinaga, T. Kageyama, M. Koizumi, K. Ando, M. Takase, M. Iyoda, J. Org. Chem. 2013, 78, 9205-9213; i) U. Páramo-García, B. A. Frontana-Uribe, P. Guadarrama, V. M. Ugalde-Saldívar, J. Org. Chem. 2010, 75, $7265-7272$.

[7] a) B. K. Banik, S. Samajdar, I. Banik, J. Org. Chem. 2004, 69, 213-216; b) M. Biava, G. C. Porretta, G. Poce, A. De Logu, M. Saddi, R. Meleddu, F. Manetti, E. De Rossi, M. Botta, J. Med. Chem. 2008, 51, 3644-3648.

[8] A. P. Decaprio, Mol. Pharmacol. 1986, 30, 452-458.

[9] a) D. R. Worrall, S. L. Williams, F. Wilkinson, J. E. Crossley, H. Bouas-Laurent, J.-P. Desvergne, J. Phys. Chem. B 1999, 103, 9255-9261; b) J. K. Thomas, Chem. Rev. 1993, 93, 301-320; c) H. Garcia, H. D. Roth, Chem. Rev. 2002, 102, $3947-$ 4007.

[10] C. Zhu, X. Ji, D. You, T. L. Chen, A. U. Mu, K. P. Barker, L. M. Klivansky, Y. Liu, L. Fang, J. Am. Chem. Soc. 2018, 140, 18173-18182.

[11] X. Chen, X. Wang, Y. Sui, Y. Li, J. Ma, J. Zuo, X. Wang, Angew. Chem. Int. 
Ed. 2012, 51, 11878-11881, Angew. Chem. 2012, 124, 12048-12051.

[12] a) T. Nishinaga, K. Komatsu, Org. Biomol. Chem. 2005, 3, 561-569; b) T. Nishinaga, R. Inoue, A. Matsuura, K. Komatsu, Org. Lett. 2002, 4, 4117-4120.

[13] a) J. W. Lee, S. Samal, N. Selvapalam, H.-J. Kim, K. Kim, Acc. Chem. Res. 2003, 36, 621-630; b) R. Eelkema, K. Maeda, B. Odell, H. L. Anderson, J. Am. Chem. Soc. 2007, 129, 12384-12385; c) B. Tang, J. Zhao, J.-F. Xu, X. Zhang, Chem. Sci. 2020, 11, 1192-1204.

[14] A. Y. Ziganshina, Y. H. Ko, W. S. Jeon, K. Kim, Chem. Commun. 2004, 806807. 